DOI 10.37882/2223-2982.2020.09-2.12

\title{
РОЛЬ СОПРОВОДИТЕЛЬНОГО (К РЕЗЮМЕ) ПИСЬМА В АНГЛОЯЗЫЧНОМ СЕТЕВОМ БИЗНЕС-ДИСКУРСЕ
}

\section{THE ROLE OF THE COVER LETTER IN THE ENGLISH-LANGUAGE INTERNET BUSINESS DISCOURSE}

\section{A. Pashina \\ M. Deneko \\ E. Sharipova}

Summary: The article analyzes the importance of a cover letter in the English-language segment of the Internet. The relevance of the research is related to the influence of American business communication patterns on national business correspondence systems, which, due to the development of digital technologies, are being integrated into the global network. The authors explore the specifics of the cover letter genre formation, highlighting a number of its subgenres. In conclusion, a linguistic and cultural interpretation of the role of this genre in Western business culture is given.

Keywords: English-language Internet business discourse, cover letter, cultural concept.
Пашина Алёна Владимировна

к.филол.н., доцент, Тюменский индустриальный университет

pashinaav@tyuiu.ru

Денеко Марина Витальевна

к.п.н., доцент, Тюменский индустриальный университет denekomv@tyuiu.ru

Шарипова Эльвира Маннуровна к.с.н., дочент, Тюменский индустриальный университет elvira_sha2009@mail.ru

Аннотация: В статье анализируется значение сопроводительного (к резюме) письма в англоязычном сегменте сети Интернет. Актуальность исследования связана с влиянием шаблонов американской деловой коммуникации на национальные системы бизнес-корреспонденции, которые, благодаря развитию цифровых технологий, активно интегрируются в глобальную сеть. Авторы исследуют специфику становления жанра сопроводительного письма, выделяя ряд его подвидов. В заключении дана лингвокультурологическая интерпретация роли данного жанра в деловой западной культуре.

Ключевые слова: англоязычный бизнес-дискурс, сопроводительное (к резюме) письмо, лингвокультурологический концепт.

История деловой корреспонденции на английском языке начинается с XV века. Английские купцы все чаще пользовались народным языком, однако латынь была языком официальных английских документов, а французский был языком королевского двора. Многие из самых ранних деловых и административных писем, написанных на английском языке, содержали набор правил, называемых Ars dictaminis, представлявших собой формальную и сложную модель, наследованную из латинской риторики. Необходимая схема организации была следующей: адрес, приветствие, уведомление, изложение, распоряжение, прощание, аттестация и дата. Несмотря на то, что диктамен (dictamen) почти исчезает в шестнадцатом веке [10], в каком-то смысле, он сохранился до сегодняшнего дня в структуре официального сообщения. Современные официальные письма имеют дату, обращение, комплиментарную концовку. Логичность, риторическая последовательность и композиционная выверенность -основные черты английского письменного делового стиля [4].

Существует мнение, что первое Curriculum vitae (CV), адресованное потенциальному работодателю, было написано Леонардо да Винчи [8]. Однако массовая необходимость в письменных обращениях к работодателю появилась в индустриальную эпоху в связи с развитием рынка труда. Начиная с 1930-х годов, “сопроводительное письмо « (cover letter) дает объяснение того, что не может 
быть найдено в необработанных данных. Первое использование «сопроводительного письма» в контексте занятости относится к 23 сентября 1956 года. Поиск работы, пересмотр резюме и составление сопроводительных писем - это новые навыки для фрагментированной экономики. Расцвет жанра сопроводительного (к резюме) письма приходится на 90-е годы XX века: именно в этот период публикуются различные руководства по составлению этого документа [8].

Сопроводительное письмо в англоязычном бизнесдискурсе прикладывается к резюме и является частью job application / заявления о приеме на работу. Несмотря на дискуссии, возникающие в англоязычном сегменте сети Интернет по поводу необходимости сопроводительного письма в XXI веке, по результатам исследования ResumeLab, сопроводительное письмо является важным компонентом процесса принятия решений среди 83\% менеджеров по найму, рекрутеров и HR-персонала [11 ].

С одной стороны, концепт «сопроводительное письмо» по-прежнему важен в западной корпоративной культуре как один из маркеров универсальной коммуникативной категории «свой-чужой».[3, с.143] С другой стороны, в настоящее время в английском языке нет единого, общепринятого словосочетания для обозначения СП (cover letter, covering letter, application letter, letter of application, motivation letter, letter of intention и т.д.), что говорит о процессах дальнейшей эволюции этого жанра деловой корреспонденции.

В статьях, размещенных на экспертных сайтах по поиску работу сети Интернет, в большинстве случаев употребления варианты cover letter/ covering letter/ application letter / letter of application взаимозаменяемы. Часть текстов противопоставляет application letter и cover letter: «Письмо-заявка и сопроводительное письмо - это две совершенно разные вещи. Шаблон письма о приеме на работу - это письмо, содержащее ваши намерения относительно работы, в то время как сопроводительное письмо представляет кандидата и обычно подается вместе с резюме. Написание сопроводительного письма и написание письма с заявлением о приеме на работу следуют почти одним и тем же рекомендациям, но отличаются тем, как они должны быть представлены» [5]. В качестве отличительных черт application letter указывают объем, внимание к деталям, самодостаточность: coverletter/ covering letter всегда привязано к резюме, application letter вполне самостоятельный документ, заявляющий о намерении занять вакансию и перечисляющим все необходимые качества кандидата.

Motivation letter, letter of purpose, personal statementсравнительно новые подвиды СП, не имеющие, в отличие от cover letter/ covering letter /application letter дефиниций в словарях современного английского языка [3, с.135]. Указанные субжанры СП требуются как заявле- ние о намерении в ряде специфических ситуаций: поступление в университет, присоединение к волонтерскому сообществу/некоммерческой организации, заявление о приеме на стажировку, сообщение о желании работать в компании.

В западной системе высшего образования победа в конкурентной борьбе за стипендию/место в магистратуре может быть обеспечена безупречным мотивационным письмом, подчеркивающим достоинства кандидата и свидетельствующим о его несомненно высокой осознанности и мотивации. Мотивационное письмо (Motivation letter/motivational letter) «объясняет причину, по которой вы, как абитуриент, были бы идеальным кандидатом на университетскую программу/стипендию, на которую вы претендуете, что требует детального изучения общей академической среды университета и различных программ со стороны студента. Обычно в мотивационном письме соискатель часто упоминает о своей квалификации и достижениях за последние несколько лет» [7]. Мотивационное письмо может понадобиться при оформлении визы в некоторые страны (Канада, Австралия), при аренде или покупке жилья: иногда арендодатель или члены закрытого кондоминиума достаточно придирчиво рассматривают представленные кандидатуры.

В ряде случаев термины motivation letter/motivational letter /letter of motivation используются как синонимы letter of intention/letter of interest: «Письмо о заинтересованности - это вступительное письмо, адресованное организации, которая не обязательно может иметь работу, доступную для заявителя. Написание письма о заинтересованности сообщает о желании работать с целевой компанией, если появится такая возможность» [9]. Главное отличие letter of intention/letter of interest/letter of motivation от cover letter/application letter - время написания письма. Письмо заинтересованности может быть подано в любой момент, в то время как сопроводительное (к резюме) письмо обычно привязано к определенной вакансии.

Итак, несмотря на доводы критиков о том, что с развитием готовых анкет на онлайн-платформах по трудоустройству СП отживает свой век $[8,11]$, разнообразие новых вариантов вербализации концепта «сопроводительное письмо» говорит о важности данного жанра. На наш взгляд, этот феномен объясняется спецификой западной деловой культуры.

Соединенные штаты Америки, входящие в число лидеров мировой экономики и генерирующие две трети контента англоязычного бизнес-дискурса, по классификации Э. Холла, принадлежат к странам с низкоконтекстной культурой (Low-context cultures) - это культуры, в которых большая часть информации содержится в словах, а не в контексте общения, люди открыто выражают свои желания, намерения, не предполагая, что их можно по- 
нять из ситуации общения. Низкоконтекстные культуры отличает:

1. прямая и выразительная манера речи;

2. невербальное общение менее значимо;

3. всё должно быть выражено словами;

4. конфликт созидателен;

5. в отдельных случаях возможно открытое выражение недовольства [6].

В целом стиль англоязычной деловой корреспонденции принято считать «прямым коммуникативным стилем», подразумевающим «использование таких речевых средств и дискурсивных стратегий, которые ясно и недвусмысленно позволяют понять коммуникативные намерения адресанта. Адресат может легко декодировать высказывание адресанта без привлечения дополнительного контекста»[4]. Такая стратегия общения связана с желанием сэкономить свое и чужое время: «Time is money».

Цель СП - представить заявителя как уникального профессионала, соответствующего требованиям вакансии, установить заочный личный контакт с лицом, принимающим решение о найме, мягко убедить его/ее в необходимости дальнейших действий (рассмотрение резюме, приглашение на собеседование). Податель СП явно и недвусмысленно заявляет о своих намерениях занять вакансию, в качестве аргументов используя информацию, изложенную особым, выгодным для составителя образом. Современный пакет документов job application транслирует уверенность в равных возможностях любого кандидата, подкрепляемую антидискриминационными движениями, что приводит к трансформации шаблонов традиционного резюме в англоязычном сегменте сети Интернет [2]. Сокращение объема СП, использова- ние визуального структурирования (bullets / графическое выделение пунктов), отказ от традиционных стилистических клише, сближение с разговорными формами современного языка используется для усиление эффективности средств воздействия на адресата [3, с.143].

Одновременно с этой тенденцией расширение функций motivation letter/motivational letter/letter of motivation до letter of intention/letter of interest или синонимическое использование motivation letter/motivational letter и cover letter говорит об усилении концепта мотивация западной культуре. Индивидуализм, заявленный как одно из специфических черт американской культуры, характеризуется предельной ориентацией индивидуумов на личные интересы [1]. Сущность сопроводительного (к резюме) письма - открытое выражение и признание этих интересов, демонстративная высокая оценка своих профессиональных и надпрофессиональных навыков (hard skills /soft skills).

Таким образом, сопроводительное письмо, с одной стороны, как и любое официально-деловое письмо, содержит традиционные черты английской деловой корреспонденции, с другой, отражает новейшие тенденции в развитии цифровых бизнес-коммуникаций. Субжанры СП в современном английском языке свидетельствуют о процессе дальнейшей спецификации текстовых шаблонов, функции которых связаны с одной из важнейших сфер жизни человека в XXI веке - самоактуализации, самопрезентации и продвижении себя как профессионала в высококонкурентной среде постиндустриального общества.

\section{ЛИТЕРАТУРА}

1. Оксинойд К.И. Типология организационных культур Герта Хофстеда //Библиотека управления [Электронный ресурc]. - URL: https://www.cfin.ru/ management/people/culture/Hofstede.shtml (дата обращения: 17.08.2020).

2. Пашина А.В., Омелаенко Н.В., Денеко М.В. Специфика вербализации концепта ЕMPOYEЕ в шаблонах резюме англоязычного бизнес-дискурса //Современная наука: актуальные проблемы теории и практики. Серия «Гуманитарные науки». 2019. № 10. С. 160-164.

3. Пашина А.В., Омелаенко Н.В., Чалых Н.А. Концепт Cover letter / Сопроводительное письмо в современном сетевом англоязычном бизнес-дискурсе // Гуманитарные и социальные науки. 2020. № 3. С. 133-143.

4. Стеблецова А.О. Дискурсивно-лингвистические особенности делового коммуникативного стиля // Вестник ТГУ. 2009. №12. -URL: https://cyberleninka.ru/ article/n/diskursivno-lingvisticheskie-osobennosti-delovogo-kommunikativnogo-stilya (дата обращения: 16.08.2020).

5. Difference between Job Application Letter and Cover Letter//Template.net URL: https://www.template.net/business/letters/difference-between-job-applicationletter-and-cover-letter

6. Hall E.T. Beyond Culture. NY: Anchor Books, 1977. 281 p.

7. How to Write a Good Motivation Letter [ Электронный ресурс]. - URL: https://www.edunation.co/studyinfinland/blog/how-to-write-good-motivation-letter/ (дата обращения: 16.08.2020).

8. Lurie S. The Cover Letter: A Short History of Every Job-Seeker's Greatest Annoyance//TheAtlantic.com [ Электронный pecypc]. - URL: https://www.theatlantic. com/business/archive/2013/09/the-cover-letter-a-short-history-of-every-job-seekers-greatest-annoyance/279564 (дата 0бращения: 16.08.2020).

9. The Key Difference Between Cover Letter and Motivational Letter//Skillroads.com [ Электронный ресурc]. - URL: https://skillroads.com/blog/the-key-difference- 
between-cover-letter-and-motivational-letter (дата обращения: 16.08.2020).

10. Thomas J. Business Writing in History: What Caused the Dictamen's Demise? // Journals.sagepub.com [ Электронный ресурc]. - URL: https://journals.sagepub. com/doi/abs/10.1177/002194369903600102 (дата обращения: 16.08.2020).

11. Tomaszewski M. Are Cover Letters Necessary in 2020? (Survey)// Resumelab.com [Электронный ресурc]. - URL: https://resumelab.com/cover-letter/are-coverletters-necessary (дата обращения: 14.08.2020).

(с Пашина Алёна Владимировна (pashinaav@tyuiu.ru), Денеко Марина Витальевна (denekomv@tyuiu.ru),

Шарипова Эльвира Маннуровна (elvira_sha2009@mail.ru).

Журнал «Современная наука: актуальные проблемы теории и практики»

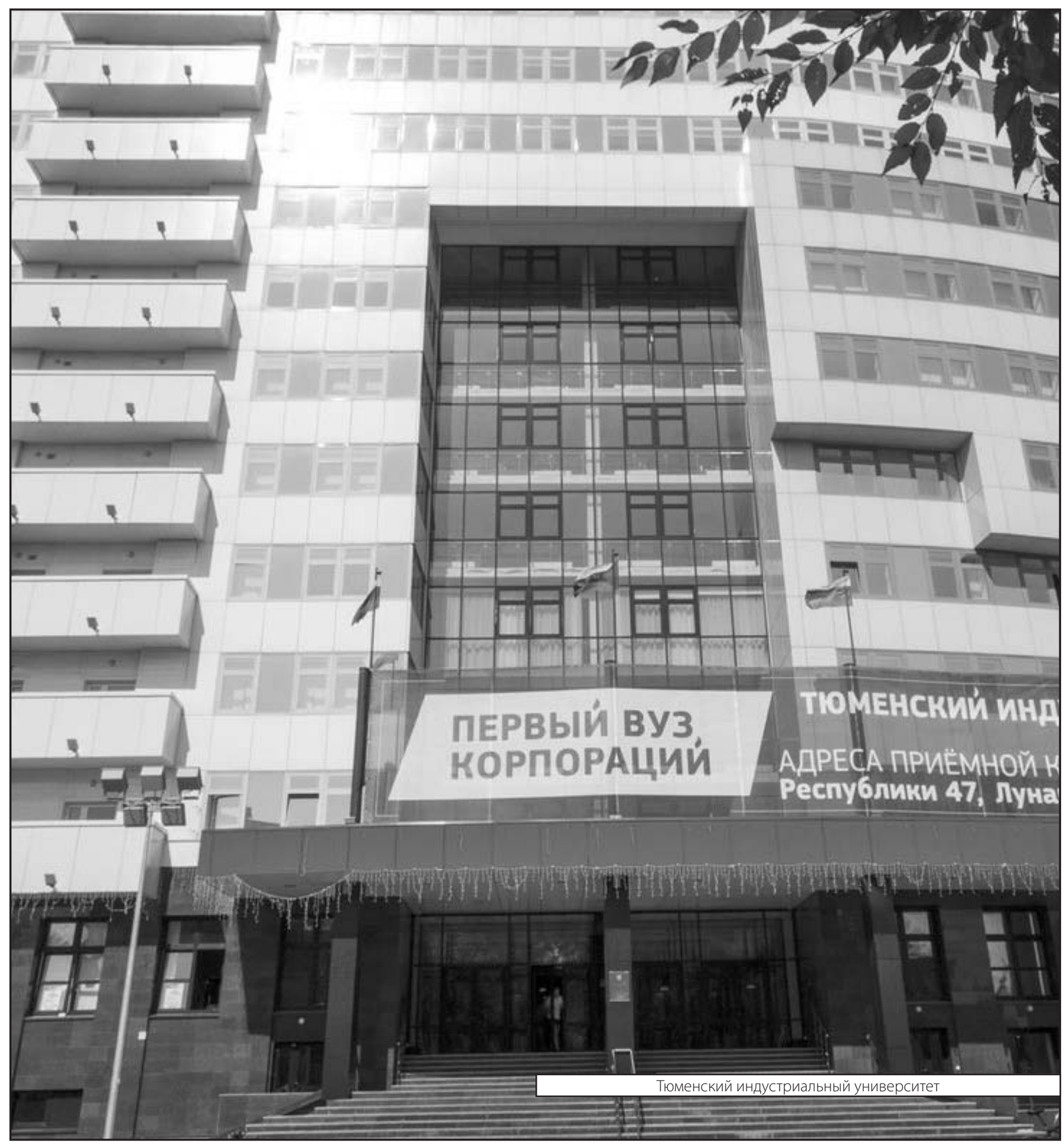

